\title{
The Narrative Dimensions Model and an exploration of various narrative genres
}

\author{
Dorien Van De Mieroop
}

KU Leuven

In the last few decades, the analytical scope of narrative studies has widened from a sole focus on "prototypical" narratives of personal experience to a wide variety of narrative genres. However interesting this may be, there are also some problems with these genres as there is not only sometimes considerable overlap between different genres, but there are also differences within these genres. Furthermore, real-life stories often consist of a mix of various genres, which makes applying genre-labels to these narratives problematic. Hence, instead of making such genre classifications, I propose an abstract "Narrative Dimensions Model" to tease out the relevant characteristics of and differences between various types of narratives. This model consists of two three-dimensional clusters, viz., one revolving around the narrator and containing the dimensions of ownership, authorship and tellership, and one revolving around the narrated events, containing the dimensions of frequency, time and evaluation. I illustrate this by a theoretical exploration of various narrative genres and I conclude by sketching the advantages of conceptualizing and scrutinizing narratives by means of this model.

Keywords: Narrative Dimensions Model, narrative genres, ownership, authorship, tellership, frequency, time, evaluation

\section{Introduction}

Stories are ubiquitous in human interaction, as people make sense of their lives through storytelling. Quite often, these stories are examples of canonical narratives of personal experience which nicely follow the structure (abstract - orientation - complicating action - resolution - coda - evaluation) as laid out in the seminal work of Labov and Waletzky (1966). But, as is generally known by now, this is not always the case, as there are of course many other types of stories that interlocutors use in their day-to-day interactions. In particular, when narrative 
research shifted focus from a structural interest to an interest into how narratives emerge in their conversational contexts (see e.g., Norrick, 2007) and what they achieve in these contexts (De Fina \& Georgakopoulou, 2008), these other narrative genres have gained increasing analytical interest. A well-known example is the wide array of small stories (Bamberg, 2006; Georgakopoulou, 2007) that researchers have scrutinized in the recent decade. Next to these small stories, which is an umbrella-term that "covers a gamut of under-represented narrative activities" (Georgakopoulou, 2006, p.123), other genres, such as the habitual narrative, have been grouped under the term "low-narrativity narratives" (Carranza, 1998), while still other genres have received attention elsewhere, such as the genre of chronicles in life story research (e.g., Linde, 1993), or narratives of vicarious experience (Norrick, 2013a), accounts (De Fina, 2009), generic narratives (Baynham, 2006) and so on. Until now, all this information on narrative genres is scattered over a variety of studies and there has not been an attempt to provide a systematic overview of these narrative genres, nor has there been an effort to scrutinize how these genres can be related to one another and what the implications of these relations are. This is nevertheless important, first of all because it is now quite hard for researchers to find their way to information regarding all these different genres and what these genres are supposed to entail. This is often quite a challenge because there are sometimes many differences within these genres as well as considerable overlap between different genres. Secondly, this lack of clarity concerning narrative genres has in some cases led to a very broad interpretation of the term "narrative". Sometimes not even the often-cited basic criterion of narrative - viz., as consisting of two narrative clauses that are characterized by a temporal progression (see e.g., Johnstone, 2001; Norrick, 2007) - is applied to identify a stretch of talk as a narrative, resulting in an over-use of the label "narrative". This would eventually result in the label becoming meaningless. Thirdly, when studying narratives in real life, researchers often find that people's everyday storytelling consists of a mix of various genres. This mix is hardly ever coincidental, and thus it is useful to carefully tease out the various characteristics of these narratives and their interrelatedness, without necessarily having to choose a specific genre label. Fourthly, the comparative study of narratives of personal experience in various cultural contexts has also revealed many variations vis-à-vis Labov and Waletzky's (1966) description of stories. For example, it was found that Asian children's narratives differed from American children's in various ways, e.g., Japanese children focus more on "collections of experiences" in their stories (Minami \& McCabe, 1995), which is also the case for Taiwanese children, who were also found to evaluate their narration less (Chang \& McCabe, 2013). Of course, these variations cause problems when attempting to fit these narratives into the "narrow" definition by Labov and Waletzky, nor do these narratives always constitute a genre that 
is entirely different from the narrative of personal experience. Hence, a model that can account for all these differences, issues and variations in and between narratives without having to apply a genre classification could solve these problems.

Before embarking on this endeavor, it is important to first clarify what I understand by the concept of "genres". In many approaches, such as ESP (e.g., Swales, 1990) and SFL (e.g., Martin \& Rose, 2008), "genres" have been studied with a primary interest in deriving a number of genre-specific characteristics which can be captured, respectively, in an analysis of "moves" in ESP or in "schemes" in SFL. Given that this research has led to genre-based pedagogy, emphasis has quite strongly been placed on "teaching students the formal, staged qualities of genres" (Hyon, 1996, p.701). As such, the concept of "genre" has become quite strongly linked to fitting oral or written texts into genre classifications. However, from a descriptive perspective, it is often more important to bring the "fuzzy fringes of genre to the center of the intellectual enterprise", as Briggs and Bauman argue (1992, p.145). Drawing on the work by Bakhtin on intertextuality and "complex genres" (1986), they propose a less static approach to genres, in line with a conceptualization of genres as orienting frameworks for the production as well as for the reception of discourse (Hanks, 1987). Such orienting frameworks invite a scrutiny of "the genres and subgenres the narrator is drawing on or deviating from (constructing, thus, possibly a counter-narrative to the genre)" (Hyvärinen, 2015, p.190). As I argued above, such a perspective on the concept of genre will enable researchers to tease out the implications of the narrators' adherence to or deviation from a particular narrative genre, and as such, it will shed a clearer light on how and why narratives may be situated at the interface of a number of narrative genres.

Finally, given this constructionist perspective on genres, from which it is selfevident that storytellers continuously creatively construct and negotiate (new) narrative genres, the genre-options are, in a way, endless. Hence, this exploration can never be exhaustive, but it is intended as an analytical reference point which will enable researchers to more carefully scrutinize the varying characteristics of the narratives that people draw on in real life.

\section{Starting point}

In their work on conversational narratives, Ochs and Capps observed that "narrative bows to no simple generic blueprint that sets it apart once and for all from other forms of discourse" (2001, p.18). As a solution for this variety, they proposed to examine narratives "in terms of a set of dimensions that a narrative displays to differing degrees and in different ways", but that are "always relevant to 
a narrative, even if not elaborately manifest" (Ochs \& Capps, 2001, p.19, italics in the original). In particular, they proposed five dimensions, viz., tellership, tellability, embeddedness, linearity and moral stance, which they based on their observations in relation to the conversational narratives in their corpus as well as other research on non-canonical narratives that was available twenty years ago.

In this article, I draw on Ochs and Capps' conceptualization of dimensions, and I propose to update and extend their dimensions into a multi-dimensional model. In particular, this new model is based on the findings regarding noncanonical narrative genres that have emerged in research in the last few decades. ${ }^{1}$ These formed the basis of my inventory of the characteristics of these many narrative genres, which I then converted into dimensions on a more abstract level. I subsequently integrated all these findings into a model of dimensions which have thus been previously identified as relevant for narrative research by at least one, but often quite a few studies. This resulted in a multi-dimensional model in which, in comparison to Ochs and Capps' dimensions, there is one fully overlapping dimension, viz., tellership. Furthermore, there is some overlap with the other dimensions (e.g., linearity can be related to the dimension of time and tellability to frequency), but the dimensions of this model tend to represent continua on a more abstract level so that they can cover as much as possible of the extensive gamut of narrative genres that have been discussed in recent years.

Finally, I argue that it is important to conceptualize narratives by means of such a model rather than in terms of one genre versus another, because it simultaneously uncovers the gradient, rather than black-and-white, nature of these dimensions as well as the multi-dimensionality of narrative genres. This will enable researchers to move away from the need to classify non-canonical narratives as, for example, "habitual" or "hypothetical", and instead it will permit analysts to situate narrative genres in a multi-dimensional orienting framework which does justice to the fluid and emergent nature of narratives.

\section{Operationalization: The Narrative Dimensions Model}

In order to operationalize this multi-dimensional nature of narratives in a graspable way, I discern six dimensions that can be grouped in two clusters of three

1. This literature review on narrative genres has been mainly situated in the domains of discourse analysis, interactional sociolinguistics and anthropological linguistics, but occasionally also in the domains of stylistics and SFL. Given the vast amount of studies on narrative, this overview of narrative genres is of course not exhaustive. 
dimensions each. These clusters revolve either around the narrator or around the narrated events.

- The narrator

- Dimension of ownership (from non-personal/vicarious experience over undefined ownership to personal and shared experience)

- Dimension of authorship (from speaking in one's own name, over speaking on behalf of oneself and others to speaking about others and assuming a generalized perspective)

- Dimension of tellership (from a single teller to various forms of collaborative tellership, see also Ochs and Capps' tellership-dimension (2001))

- The narrated events

- Dimension of frequency (from events that have not or may not have happened/happen over single, unique events to multiple and generalized events)

- Dimension of time (from past over present and future to temporally undefined)

- Dimension of evaluation (from no evaluation, over medium to high evaluation)

Given the three-dimensional nature of both the "narrator"- and the "narrated events"-cluster, the dimensions of each cluster can thus be integrated into a threedimensional cube, in which each dimension's gradient is represented by a theoretical scale of o to 10o. This model is visualized in Figure 1.
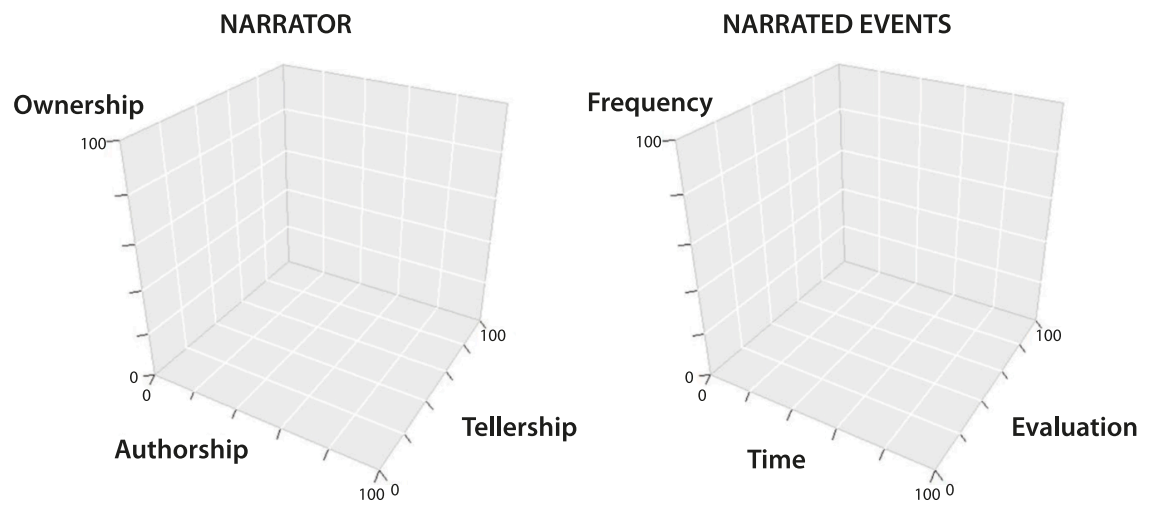

Figure 1. Narrative Dimensions Model

In particular, the content of the gradients of each dimension may be represented in more detail as in Figures 2 and 3. 


\section{NARRATOR}

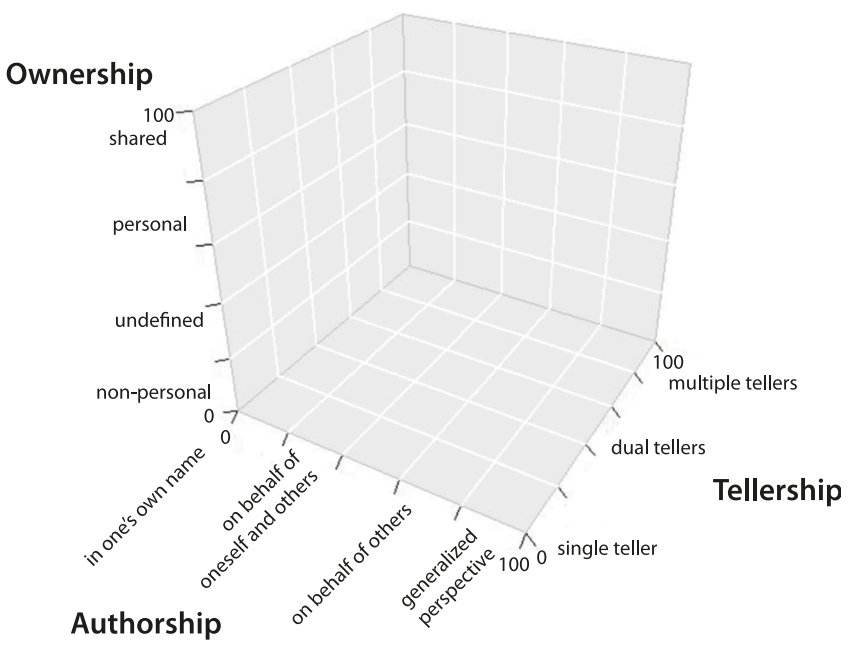

Figure 2. Detailed representation of the "narrator"-cluster of the Narrative Dimensions Model

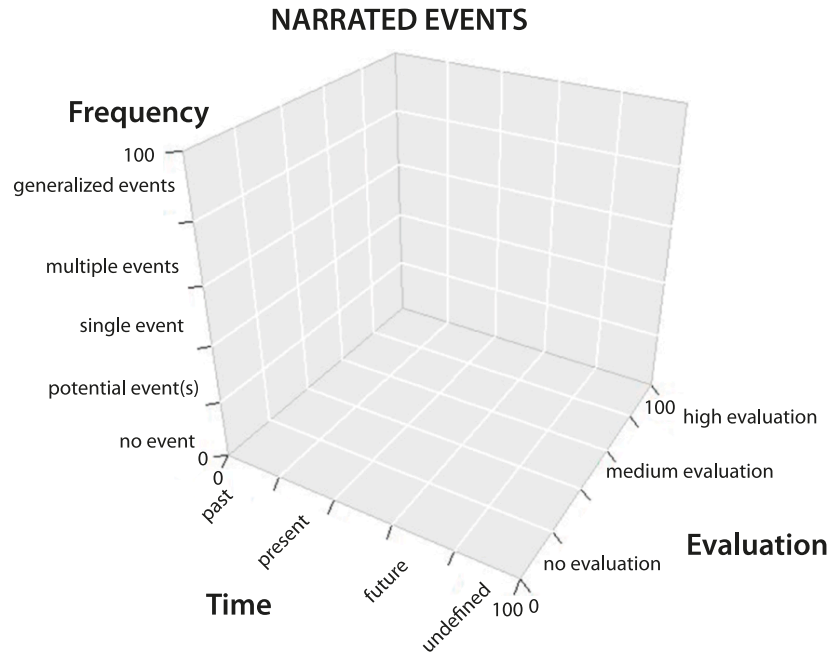

Figure 3. Detailed representation of the "narrated events"-cluster of the Narrative Dimensions Model

Hence, by means of the Narrative Dimensions Model, it is possible to situate the various narrative genres in terms of each of these dimensions in the cubes and as such visually represent each narrative's unique position. So for example, 
a canonical NoPE would be situated in the model as represented in Figure 4, because it concerns a narrative that revolves around a single event in the past, that the narrator personally experienced and about which $\mathrm{s} /$ he talks as the sole narrator in his/her own name, and that is evaluated in the story.

NARRATOR

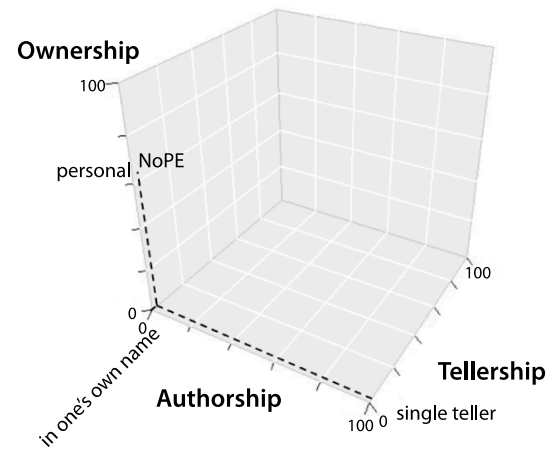

NARRATED EVENTS

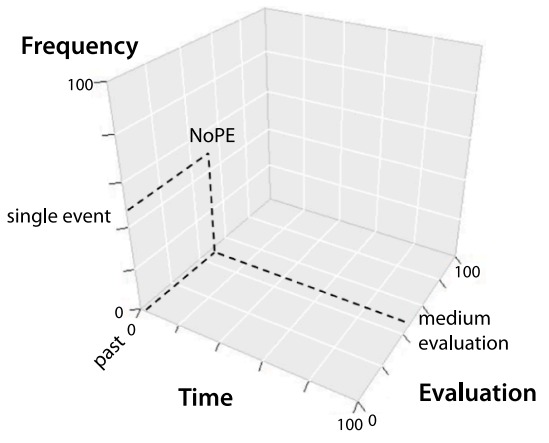

Figure 4. The prototypical narrative of personal experience (NoPE) situated in the Narrative Dimensions Model

It is important to note, though, that the representation of the Narrative Dimensions Model by means of the "narrator"- and the "narrated events"-cluster, is meant in a theoretical way, rather than a calculation, as the scale from o to 100 may suggest. This scale is only used to represent the gradient nature of these dimensions and so the numbers are only indicative ${ }^{2}$ and are used solely to identify the "theoretical" coordinates of individual narratives in order to localize them in the plots (see e.g., Figure 4). Hence, the visual representation should be considered as theoretical, instead of quantitative and the scale from o to 100 as merely a gradient which is practical for visualization purposes.

\section{Narrative dimensions in relation to non-canonical narratives}

In this section, I now show how the model brings structure to the wide variety of non-canonical narrative genres that have been discussed in various studies focusing on narrative. A caveat is in place here: my aim is not to present an exhaustive overview of all the non-canonical narrative genres that have been discussed up

2. The implied percentages do not represent a particular quantity, as this would of course be meaningless for quite a few dimensions (e.g., the dimension of time) and not particularly meaningful when counting is possible (e.g., the dimension of tellership). 
till now, but rather to provide an insight into the relations between a number of these non-canonical genres which have received quite some analytical attention. At the same time, this overview will give more depth to the content of each of the dimensions of the model and will thus make it applicable to genres that I have not included in my overview, as well as for newly emerging genres.

I operationalize this by discussing various narrative genres that are specifically marked in terms of a particular narrative dimension and comparing them to other genres in that respect. Hence, the discussion will be relatively monodimensional and it is crucial to note here that this is highly artificial, as a narrative actually has a (non-quantitative) "score" on each of the six dimensions, as was shown for the prototypical NoPE above, rather than the one dimensional perspective that I adopt here. Such a mono-dimensional discussion is only possible because this overview focuses on abstract narrative genres, rather than real-life storytelling. In line with this, only abstract examples of potential types of stories will be discussed here, as analysing real-life narratives would take up too much space (but for examples of authentic non-canoncial narratives, see chapter 3 in Clifton, Schnurr, \& Van De Mieroop, 2020; and for an extensive application of this model on real-life narratives, see Van De Mieroop, forthcoming). So in this article, I limit myself to discussing in theoretical terms how non-canonical narratives stand out in terms of a particular narrative dimension, as such also making the relations between these genres more tangible.

I now subsequently discuss the dimensional cluster revolving around the narrator, after which I will focus on the three dimensions related to the narrated events.

\section{Narrator}

\section{Dimension of ownership}

One of the essential elements of NoPEs, is that these narratives are all related to events that the narrator personally experienced. This may be considered as a crucial element of these types of narratives, as the subtitle of Labov and Waletzky's seminal work ("oral versions of personal experience" (1966)) also suggests. Given their focus on interviews in which stories of violence (e.g., shootings or street fights) or "danger of death stories" were probed for, it is quite natural that these storytellers tended to focus on events that they encountered themselves. Moreover, and more generally speaking, Shuman - also drawing on Sacks (1992) maintains that it is a basic rule for conversational narrative that the person who 
"had" the experience, therefore "owns" it and is entitled to tell the story of this experience (Shuman, 2005, p.155).

However, next to telling stories about the personal experiences one "owns", narrators may also focus on events towards which they have another ownership relation. First, they can tell stories about events that they did not experience themselves. In particular, there are "stories that travel beyond the people whose experiences they describe" (Shuman, 2015, p.53), viz., the so-called narratives of vicarious experience. In some cases, it is fairly self-evident that people tell such stories, for example if one has witnessed an accident, the witness may in some cases be a more reliable teller than the victim, despite not having experienced the event on a first-hand basis (Sacks, 1992). In other cases, this may be far less self-evident, for example when narrators tell "stories about other people engaged in actions that the tellers did not witness" (Norrick, 2013a, p.385). In particular, such narratives of vicarious experience create problems in terms of evaluation, as Labov and Waletzky (1966) already observed. In order to compensate for this lack of "evaluation [that] happens naturally", tellers "have to establish a stance toward the events and characters from the ground up" (Norrick, 2013b, p. 293), as shown in Norrick's analysis of narratives of vicarious experience in Barack Obama's speeches (2013b) or in my own analysis of such narratives in job interviews (Van De Mieroop, 2019). Second, it may also be undefined who "owns" the experience, for example when the narrator tells a generic narrative and assumes a generalized perspective, e.g., by means of the generic you-form (see the following dimension). In such cases, the narrated events tend to be generalized (see the frequency dimension) and set in an undefined time frame (see the time dimension), thus rendering the exact experience vague and leaving the question open whether there actually is a real person who experienced these events and who can thus claim ownership of the narrative, or, alternatively, whether there are perhaps more people who experienced those kinds of events.

Finally, at the other end of the continuum, we find narratives of shared experience, which report on events of which various people have ownership. This shared ownership is of course often the case, as stories tend to involve various storyworld characters who may all, to a greater or lesser extent, be entitled to act as narrators. Especially when (some of) the storyworld characters are co-present during the storytelling event, there is not a single person who is self-evidently entitled to assume the role of narrator. This may result in collaborative tellership (see the tellership dimension) in which the shared ownership of the story may become interactionally visible by the co-production of the story by two or more narrators. For example, when two friends think they encountered a UFO, they may tell about it together, in choral or alternating dual tellership constellations. Alternatively, only one friend may narrate this story and $\mathrm{s} /$ he may thus act 
as the sole narrator of a story with shared ownership. In such cases, this single tellership may be explicitly accounted for by claims to higher storytelling rights in comparison to the other co-present storytelling candidates. For example, when telling the story of a dispute, the instigator of the dispute may have higher storytelling rights - because of more extensive knowledge of the dispute's background for example - than a bystander and so the former may act as the undisputed single teller of these events in spite of shared ownership of the experience of the events with the latter.

\section{Dimension of authorship}

In canonical NoPEs, storytellers typically tell stories in their own name. In Goffman's terms, they thus assume the position of principal vis-à-vis the story, meaning that the teller thus constitutes the sole "party to whose position the words attest" (Goffman, 1979, p.17). In other cases, narrators may also speak on behalf of, or about others, thus not assuming the role of the sole principal of the story, but rather that of the author, viz., as "the agent who scripts the lines", or even of the animator or "sounding box" (Goffman, 1979, p. 17) when reciting pre-scripted lines. For example, when telling collective stories (Van De Mieroop, 2015), narrators relate the experiences of a particular ingroup or a social category, which may potentially result in the telling of categorical narratives (Van De Mieroop, Miglbauer, \& Chatterjee, 2017). In such narratives, narrators may refrain from presenting themselves as the sole principal of the story, but may instead emphasize their membership of certain morally loaded categories (cf. Membership Categorization Analysis, see Sacks, 1986). For example, a woman may talk about her experiences with sexism at work from a collective perspective, viz., in terms of what happens to women in general in the workplace (see Van De Mieroop et al., 2017). Furthermore, narrators may also tell stories about others, e.g., when "scripting the lines" of a narrative of vicarious experience, when acting as a "talking machine" and animating a traditional, pre-scripted narrative or when performing any role in-between.

Moreover, narrators may also blur who the principal or author of the story is by adopting a generalized perspective. This is the case when storyworld characters are presented as generalized actors - see e.g., stories about "the head of the family" rather than a 1st person protagonist in the generic narratives discussed by Baynham (2006) - or indefinite persons, e.g., expressed through impersonal pronouns such as "one" (Kitagawa \& Lehrer, 1990) and generic pronominal forms such as the generic you-form (Stirling \& Manderson, 2011). While these forms often still index the speaker (O'Connor, 1994, p.47), they also tend to have a generalizing meaning, as such widening the scope of the story experience far beyond 
the purely personal experience of the narrator. Hence, this obfuscates who "had" the experience (cf. the ownership dimension above), which may sometimes raise issues of who has - or takes - the authority to make such generalizations and to speak on behalf of an entire group.

\section{Dimension of tellership}

Given the specific local context in which Labov and Waletzky's stories were elicited (1966), viz., researcher-led interviews, and the continuing interest in socalled "big stories" that tended to be derived from "interrogative venues" (Freeman, 2006, p.132) often involving one "questioner" and one "answerer/storyteller", the impression may have emerged that stories are usually told by one person. This is because in stereotypical interview settings, interviewers tend to be unknowing recipients of stories they have no involvement in. It is nevertheless important to note that even in such cases of single tellership, storytelling is often also collaborative to a certain extent, on the one hand because storytellers design their narratives for their audiences (Goodwin, 1984). For example, (non-)verbal audience reactions may incite narrators to elaborate on a certain aspect of their story, such as providing background information necessary to understand the story. On the other hand, interviewers tend to also have a significant impact on the selection and construction of narratives (see e.g., Van De Mieroop \& Clifton, 2014).

Furthermore, many researchers have drawn attention to situations in which tellership is shared with other interlocutors in one way or another, thus resulting in a form of collaborative storytelling. For example, when two participants have jointly experienced an event, there may be a dual tellership-constellation in which the storyteller may be assisted by this other knowledgeable participant, who, as a potential co-teller, may sometimes take over the role of storyteller (Lerner, 1992), or the co-tellers may do complementary work, such as dramatizing the narration (Mandelbaum, 1987). Other examples that tend to be inviting for co-narration, thus often resulting in multiple tellership-constellations, are (1) humorous narratives, in which co-tellers typically provide details in order to enhance the humor of the story presentation (Norrick, 2004), (2) digital narratives in which a potentially vast network of tellers who are not necessarily co-present in time and space, may co-produce a narrative (Page, Harper \& Frobenius, 2013, p.194), or (3) narratives that are shared in a particular community of practice in which they may be jointly recontextualized at various occasions, often only through a few brief references (Georgakopoulou, 2002). As such, the tellership of narratives may be shared in a variety of very different ways, and these may relate to variable extents to the dimension of ownership, as narrators 
may be drawing on shared first-hand experience of the source events of a story (e.g., the two friends who think they encountered a UFO, cf. above), or on shared experiences with similar events (e.g., two women who both experienced similar sexist remarks and combine them into a shared narrative about repeated, habitual experiences), or even on shared hearsay knowledge (e.g., the collaborative telling of a narrative of vicarious experience, such as a news event).

\section{Narrated events}

\section{Dimension of frequency}

Regarding this dimension, it is first of all important to observe that NoPEs typically centre around events that are presented by the narrator as having really happened. Whether this is truly the case, is a matter that does not tend to be of interest to narrative researchers, who rather tease out how narrators design their stories so that they are perceived as truthful (cf. Atkinson \& Delamont, 2006; Clifton \& Van De Mieroop, 2016; Schoofs \& Van De Mieroop, 2019). However, the narrated events are not always presented as factual, as narrators may sometimes specifically focus on "disnarrated events", viz., "events that do not happen though they could have" (Prince, 1992, p.30). Such counterfactual narratives may have a variety of effects, such as creating suspense or surprise, giving an advance insight into what could happen (but does not), presenting a parallel or alternative reality, and deceiving the reader (see also Norrick, 2018; Prince, 1992). Overall, in mundane interaction, such a counterfactual narrative may serve several functions; for example it may work as "an evaluative device because it constitutes the narrator's commentary on what did happen", while it may also perform a focalizing, an explanatory and a claim-backing function (Carranza, 1998, p. 291). Furthermore, the telling of counterfactual events may constitute an entire narrative, but, and quite often, these events may also be inserted into a narrative that reports on events that actually happened. In such cases, these counterfactual elements may appear "in phrases such as 'I wonder what would have happened if...' or 'if I had to do it over again, I would...”" (Vindrola-Padros \& Johnson, 2014, pp.1604-1605) and as such, they briefly "make the audience visualize an alternative reality" (Vindrola-Padros \& Johnson, 2014, p.1608). Similar to this, yet a bit different, are stories about potential events, namely events that could have happened, but of which it is unsure whether they did. For example, Ochs and Capps (2001) discuss a story of somebody whose watch is missing, and who tells a narrative about it possibly having been stolen, or about him possibly having lost it. In 
such cases, the events are not presented as counterfactual, but rather as events of which the factuality is unsure.

Furthermore, prototypical NoPEs typically focus on a unique sequence of events that tends to have a relatively high tellability or reportability (Labov, 1982), which is nevertheless situated within certain boundaries (Norrick, 2005). Yet, there are often occasions when instead of referring to a single event, narrators draw attention to the fact that certain events happened at a number of occasions, and this aspect of repetition is often the element that makes the story worth telling. For example, if someone receives a message from an acquaintance that expresses the latter's admiration of the former, this may be a bit odd but not particularly noteworthy or tellable. Yet, if this keeps on happening, it would be considered as stalking and the recurrent nature of these events would make the story tellable. In order to recount these events, the narrator would in that case not be able to do justice to this situation by recounting a single event (viz., one admiring message), but s/he would rather emphasize the multiplicity of the events, viz., that several messages were sent repeatedly.

In order to report on routine incidents that happened to an individual person in the past, narrators may formulate a habitual narrative, or, as Norrick (2000, p.151) calls it, a "generalized recurrent experience"-narrative. This is typically "composed of thematically organized incidents that occur regularly, without a peak in action" (Riessman, 1993, p.18). This absence of a story climax tends to result in "a less dramatic style of narrating, since such narratives cannot reproduce the blow-by-blow effect of a story about a single occasion" (Cheshire \& Ziebland, 2005, p. 24). The narrative clauses are typically not presented in the simple past tense, as is usually the case in the NoPE, but by means of "verb phrases with would and would be-ing along with used to forms" (Norrick, 2000, p. 151). In some cases, also "present time narratives" are used to report on habitual behavior (Trinch, 2003, pp.109-110), even though these also occur when a more generalized perspective is assumed (see below). In any case, in habitual narratives, the specific timing of the events that are narrated is unclear and may sometimes be presented as irrelevant, with the effect that habitual narratives "build a holistic picture of the past that speaks for itself" (Carranza, 1998, p.305). For example, when talking about her childhood days, a narrator could tell about how she "used to" walk to school and, on the way back, "would" buy some sweets and share them with the other kids with whom she "would" play outside for hours. As such, habitual narratives often transmit "an established or pre-existing interpretation" (Carranza, 1998, p.307) of the past to the story recipients. 
Finally, another narrative genre that is characterized by the suspension of the "uniqueness condition", ${ }^{3}$ is the generic narrative. Much in the same vein as in the habitual narrative, typicality and iterativity are emphasized in this narrative genre (Baynham, 2006, p.382), but the perspective that is assumed is more generalized. This is the case for the events that are presented, for which the general present is often used, but also for the storyworld characters that often take the form of generalized actors (Baynham, 2006, p.383), as discussed above (see the authorship-dimension). For example, Baynham (2006) discusses generalized stories of migration patterns that were typically told by men who took up publicspeaking positions on behalf of their communities. In such cases of "prototypical" generic narratives, both this dimension and the authorship and ownership dimensions are thus situated at the generalized or undefined ends of the continuum, and this is also the case for the following dimension.

\section{Dimension of time}

As is clear from the first part of Labov and Waletzky's definition of the NoPE ("one verbal technique for recapitulating past experience..." (1966, p.13)), narrated events are prototypically expected to be situated in the past. However, not all narratives are oriented to the past, as some stories revolve around what is happening at the moment or what may or will happen in the future, while some other stories may blur this temporal dimension and may be situated in an undefined time period.

First of all, there are stories that have a clear focus on the present, which often revolve around "very recent or still unfolding events", such as "breaking news"-stories (Georgakopoulou, 2007, p.148). This term is particularly "aimed at capturing their dynamic and ongoing nature" (Georgakopoulou, 2006, p.126), thus drawing attention to the temporal dimension of these narratives that deviates from what is canonically expected. Moreover, some digital narratives also tend to be more oriented to the present than to the past (Page, 2010). In some forms, such as Facebook status updates, the chronological aspect of these digital narratives is crucial (Page, 2010), unlike in other forms, as I discuss below.

Moreover, there are various narrative genres that are oriented to the future. A first subgenre is that of "conversational fantasy" (Norrick, 2000) or "hypothetical narratives". These are often initiated by phrases like "suppose' or 'what if X were to happen'" (Georgakopoulou, 2001, p. 1892), after which a hypothetical scenario can be developed which is often formulated in the subjunctive form (Riessman, 1993) or by means of modal verbs such as "could" and "would" (Norrick, 2000, p.131).

3. A story's sequence of events occurring "once and once only" (Baynham, 2006, p.382). 
For example, Georgakopoulou (2001) shows an interaction in which friends give each other advice by means of hypothetical scenarios on how to deal with an unrequited love. Such a scenario may often serve similar functions as the ones described above for counterfactual narratives, and it is often coupled to other narratives through argumentative relationships of, e.g., contrast or analogy (Carranza, 2015, p.66). Related to these hypothetical narratives are "stories of projected events", "projections" (Georgakopoulou, 2007) or "predictive narratives" in which "anterior narration" is realized (Prince, 1982). These are "told in the future tense and mostly involve planning a course of action" (Georgakopoulou, 2002, p. 431).

Finally, even though some digital narrative practices may have an orientation to the present (Page, 2010), this temporal dimension may also be blurred, leading to a more undefined temporality of these narratives. In particular, online narratives' "multiple nodes, pathways and dimensions depart from the linearity inherent in earlier but seminal models of narrative" (Page et al., 2013, p.192). For example, digital narratives may consist of a diversity of potential textual components, such as comments and "likes", as well as other multimodal resources, such as images, memes, videos, and hyperlinks. Because all these different elements may be drawn upon and recontextualized with a few easy clicks, the chronology of such a digital narrative may not only be hard to detect, but it is often also irrelevant, thus pointing at the undefined nature of this temporal dimension. Page et al. (2013) coined the term "networked narrative" for these digital narrative practices, by means of which they not only drew attention to the non-chronological nature of the narrative organisation in digital environments, but also to different narrator constellations, which was already briefly mentioned when discussing the tellership dimension above. Furthermore, chronology and linearity may also be (partially) irrelevant for narratives that are less oriented to coherence (cf. Hyvärinen, Hydén, Saarenheimon, \& Tamboukoun, 2010). Finally, one can easily imagine that narratives that are situated near the "generalized" end of the frequency- or the authorship-dimension (e.g., habitual, generic and categorical narratives), may also be characterized by a rather undefined temporality, thus adding to the more generalizing perspective of some of these non-canonical narrative genres.

\section{Dimension of evaluation}

As a final dimension, I draw attention to the fact that events can be evaluated to varying extents in narratives. First of all, in the prototypical NoPE, the aspect of evaluation is treated as a crucial element of storytelling, as stories' evaluative function causes the "transformation of the primary sequence, based on the a-thenb relationship, into the more complex normal form of the narrative" (Labov \& Waletzky, 1966, p.41). Moreover, next to pointing at the evaluative function that 
is present throughout a story, Labov and Waletzky also identified "evaluation" as one of the five structural elements of a prototypical story and defined it as the point of the story. This reveals the narrator's attitude towards the story by emphasizing the relative importance of some narrative units as compared to others, thus drawing the audience's attention to particular aspects of the story while deemphasizing other parts. This story's point may of course be quite varied, which has led researchers in the SFL-tradition to subcategorize narratives into anecdotes, exemplums and observations on the basis of the type of point they have (Martin \& Rose, 2008, p. 51).

However, in this model, I do not focus on the type of point, as this would lead me too far into the realm of the story content. Instead, I focus on the extent to which the evaluative function is developed in narratives. At one end of this continuum, there are narratives that merely describe, rather than evaluate, events and leave it up to the narrator to decide what the point of the story actually is. Even though there are different types of such objective-sounding narratives with an underdeveloped evaluative function, e.g., "reports" (Toolan, 2001, p.190) and "recounts" (Martin \& Rose, 2008, p.51), we zoom in on one particular genre which has received quite a bit of analytical attention, viz., the "chronicle". Chronicles are tellings of chronologically ordered events which are often used "when the speaker needs to fill in temporally organized information that is unknown to the addressee" (Linde, 1993, p. 86). Such chronicles can be defined as sequences of events that tend to be tied to one another by "and then" as a conjunctive link (Toolan, 2001, p.190) in which the events' seriality is central. Thus, in terms of evaluation, chronicles are "not designed to report and evaluate personal experience" (Labov, 2011, p. 547) and it has even been emphasized that this absence of evaluation is one of the defining features of chronicles (see e.g., Toolan, 2001, p.186). These chronicles may thus not have an explicit "single unifying evaluative point" (Linde, 1993, p.85), but such a point - or even "a multiplicity of evaluative points" (De Fina, 2003, p.98) - may nevertheless be implied. A prototypical example of such chronicles, or "chronological sequences", may be found in young children's tellings (Peterson \& McCabe, 1983).

In contrast to chronicles, which revolve mainly around the referential function of narratives, the evaluative function may also be more strongly developed than in prototypical NoPEs. This is the case for "narrative accounts", which can be situated at the other end of the evaluation-continuum. These can be defined as "recapitulations of past events constructed as responses to an explicit or implied 'why' or 'how' evaluative question by an interlocutor" (De Fina, 2009, p.240). Due to the narrator's perception of the other interlocutor's question (viz., as evaluative), the former will shape - or "recipient design" - his or her narrative in such a way so that it addresses this perceived evaluation, e.g., by formulating a narra- 
tive that explains, justifies or provides an excuse for a particular situation. This implies that accounts may occur in various forms and lengths, ranging from short and "simple recapitulations of events" to "long and complex narratives" in which various other story types may be embedded (De Fina, 2009, p. 251).

This recipient design of narrative accounts should be regarded in the broadest way as possible, as it is not only the physically-present story recipients whose evaluative stance may be oriented to in a story, but also that of a "ghostly" or "imagined" audience (Minister, 1991) that can be considered as "the virtual embodiment of the socio-cultural context of the storytelling world" (Van De Mieroop \& Clifton, 2016, p.15) and thus of particular master narratives circulating in these contexts. For example, in my own work on narrative accounts of poor people, I demonstrated that the narrators often invoked their membership of the category of "responsible mothers" to counter a master narrative that frames poor people's allegedly irresponsible behavior as the cause of their predicament (Van De Mieroop, 2011). Of course, narrators may orient their narrative accounts towards these master narratives in a variety of ways, which is one of the reasons why this narrative genre is characterized by a high degree of variability. Due to this diversity in the many shapes narrative accounts may take, I conclude this discussion by a list of characteristic features of accounts as identified by De Fina:

- "They are recapitulations of past experience constructed as responses to explicit or implicit interviewers' evaluative inquiries about how or why those experiences took place

- They involve explanations

- They are recipient designed

- They are generally oriented towards factuality

- Their structure varies a great deal as it is the emergent result of the specific questions asked and the relationships established between interlocutors." (De Fina, 2009, p. 253)

\section{Conclusions}

In this article, I drew on Ochs and Capps' concept of the dimensional approach to narratives (2001) and devised the Narrative Dimensions Model on the basis of findings from studies on narrative genres of the last few decades. This resulted in two three-dimensional clusters, viz., one revolving around the narrator and containing the dimensions of ownership, authorship and tellership, and one revolving around the narrated events, containing the dimensions of frequency, time and evaluation. 
The discussion of these six dimensions and their relation to the canonical narrative of personal experience as well as various non-canonical narrative genres has first of all shown that for each of these dimensions, there is attested variation in the literature, with narrative genres situated at all the different ends of the sixdimensional continuums. This implies that the dimensions each represent a relevant aspect of narratives regarding which narrators make choices whenever they tell a story. Moreover, the detailed discussion of these dimensions has shown that some of these dimensions may quite often be inter-related. For instance shared story ownership may more easily result in collaborative tellership constellations, and a generalized authorship-perspective may often entail the telling of generalized events in an undefined time period. Yet, these dimensions are not always and necessarily linked to one another (e.g., people may collaboratively recount a news item, which is typically a story the tellers do not have ownership of ) and so it is still clear that they are different dimensions.

Next to helping researchers to tease out more clearly the choices narrators make for each story they tell, the Narrative Dimensions Model also solves the issue that some labels of non-canonical narrative genres cover a wide variety of narratives which may come in various shapes and sizes (e.g., the narrative account). By means of this model, it is possible to pinpoint the particular similarities as well as the differences between individual narratives, which could otherwise be hidden by the categorization within one or more genres. Furthermore, people may mix a number of narrative genres (e.g., a partially generic, partially habitual narrative of vicarious experience (for an example, see Clifton et al., 2020, p.57)) or may sometimes shift from one genre to another while telling their story (for an example, see Van De Mieroop et al., 2017). By scrutinizing such narratives and the shifts within them via the Narrative Dimensions Model, researchers may really bring to the fore the intricate, usually non-arbitrary, multi-dimensional nature of narratives (for examples, see Van De Mieroop, forthcoming). In addition, the model will enable researchers to identify potential cultural differences in narration (see e.g., Chang \& McCabe, 2013). As such, this model can account in a more detailed way for the intra- and inter-genre variation that is typical of real-life narratives across various cultures, because it highlights dimensional differences as well as similarities between various narratives that may otherwise go unnoticed.

Finally, the model also helps to clarify individual deviations from expected features of particular narrative genres, while still remaining within the boundaries of the label "narrative". As mentioned in the introduction, I argue that this label should be applied cautiously, as we otherwise run the risk of ending up with an empty concept. Adhering to the basic definition of narrative as minimally consisting of two narrative clauses that are characterized by a temporal progression (e.g., Johnstone, 2001; Norrick, 2007), seems wise, but in particular cases, 
for example when non-coherent and non-chronological narratives struggle with the aspect of "temporal progression", this Narrative Dimensions Model can help to clearly account for these deviations. As such, the model enables researchers to critically scrutinize what is, or may still be considered as, a narrative, which particular choices narrators make on each dimension and how this affects the multi-dimensionality of narratives, as well as what the implications of these multidimensional choices are on how narratives function in their real-life contexts.

To conclude, I wish to draw attention to the fact that this model may potentially benefit from further extension in the future. For example, the extent to which the narrated events are presented as factual could be another relevant dimension. This is now included in the dimension of frequency, but it could be argued that this would work better as a dimension on its own. Furthermore, another avenue to potentially explore further, is the relation between narratives and their contexts of use. Ochs and Capps (2001) already included such a contextual dimension in their dimensional approach, viz., embeddedness. I decided not to develop this into a dimension, as I believe that trying to cram the relations between a narrative and its local and/or global contexts into a continuum would not be able to do justice to the variety of the relations that are possible. Moreover, depending on the approach that narrative researchers adopt, this is also relevant to differing extents (e.g., researchers in conversation analysis would typically not explore the relations between a narrative and its global, societal contexts, which is, in turn, an aspect that critical discourse analysts would tend to capitalize on in their analyses). Thus, by not including this contextual aspect and focusing on the core aspects of the narrative itself, the Narrative Dimensions Model is designed to be useful for researchers who study narrative regardless of their approach. Finally, as stories are creatively constructed over and over again, a narrator's potential to vary on well-established narrative genres is endless. This may result in the emergence of new narrative genres (e.g., in the rapidly changing domain of digital narratives, see e.g., De Fina \& Perrino, 2017)) and thus still other dimensions may become relevant in the future. These future developments could also lead to the extension of the Narrative Dimensions Model and thus it will remain important to extensively "test" - and keep on testing - this model on real-life storytelling (see Van De Mieroop, forthcoming)). For now, I hope that this six-dimensional model will help researchers in their exploration of similarities and differences between real-life narratives and the careful scrutiny of how and why stories are shaped in the intricate ways in which they are. 


\section{References}

Atkinson, P., \& Delamont, S. (2006). Rescuing narrative from qualitative research. Narrative Inquiry, 16(1), 164-172. https://doi.org/10.1075/ni.16.1.21atk

Bakhtin, M. (1986). The Problem of Speech Genres. In C. Emerson \& M. Holquist (Eds.), Speech Genres and Other Late Essays (pp. 60-102). Austin: University of Texas Press.

Bamberg, M. (2006). Stories: Big or small; Why do we care? Narrative Inquiry, 16(1), 139-147. https://doi.org/10.1075/ni.16.1.18bam

Baynham, M. (2006). Performing self, narrative and community in Moroccan narratives of migration and settlement. In A. De Fina, D. Schiffrin \& M. Bamberg (Eds.), Discourse and Identity (pp. 376-397). Cambridge: Cambridge University Press. https://doi.org/10.1017/CBO9780511584459.019

Briggs, C., \& Bauman, R. (1992). Genre, intertextuality, and social power. Journal of Linguistic Anthropology, 2(2), 131-172. https://doi.org/10.1525/jlin.1992.2.2.131

Carranza, I.E. (1998). Low-Narrativity Narratives and Argumentation. Narrative Inquiry, 8(2), 287-317. https://doi.org/10.1075/ni.8.2.04car

Carranza, I.E. (2015). Narrating and Arguing; From Plausibility to Local Moves. In A. De Fina \& A. Georgakopoulou (Eds.), The Handbook of Narrative Analysis (pp. 57-75). Chichester: Wiley Blackwell.

Chang, C.-J., \& McCabe, A. (2013). Evaluation in Mandarin Chinese children's personal narratives. In A. McCabe \& C.-J. Chang (Eds.), Chinese Language Narration: Culture, cognition, and emotion (pp.33-56). Amsterdam: John Benjamins. https://doi.org/10.1075/sin.19.04cha

Cheshire, J., \& Ziebland, S. (2005). Narrative as a resource in accounts of the experience of illness. In J. Thornborrow \& J. Coates (Eds.), The Sociolinguistics of Narrative (pp. 17-40). Amsterdam: John Benjamins. https://doi.org/10.1075/sin.6.02che

Clifton, J., Schnurr, S., \& Van De Mieroop, D. (2020). The Language of Leadership Narratives: A Social Practice Perspective. Abingdon: Routledge.

Clifton, J., \& Van De Mieroop, D. (2016). Master Narratives, Identities, and the Stories of Former Slaves. Amsterdam: John Benjamins. https://doi.org/10.1075/sin.22

De Fina, A. (2003). Identity in Narrative, A study of Immigrant Discourse. Amsterdam/Philadelphia: John Benjamins Publishing Company. https://doi.org/10.1075/sin.3

De Fina, A. (2009). Narratives in interview - The case of accounts; For an interactional approach to narrative genres. Narrative Inquiry, 19(2), 233-258. https://doi.org/10.1075/ni.19.2.03def

De Fina, A., \& Georgakopoulou, A. (2008). Analysing narratives as practices. Qualitative Research, 8(3), 379-387. https://doi.org/10.1177/1468794106093634

De Fina, A., \& Perrino, S. (Eds.). (2017). Storytelling in the Digital Age: New challenges [Special issue]. Narrative Inquiry, $27(2)$.

Freeman, M. (2006). Life "on holiday"? In defense of big stories. Narrative Inquiry, 16(1), 131-138. https://doi.org/10.1075/ni.16.1.17fre

Georgakopoulou, A. (2001). Arguing about the Future: On Indirect Disagreements in Conversations. Journal of Pragmatics, 33(12), 1881-1900.

https://doi.org/10.1016/So378-2166(oo)00034-5 
Georgakopoulou, A. (2002). Narrative and identity management: discourse and social identities in a tale of tomorrow. Research on Language and Social Interaction, 35(4), 427-451. https://doi.org/10.1207/S15327973RLSl3504_2

Georgakopoulou, A. (2006). Thinking big with small stories in narrative and identity analysis. Narrative Inquiry, 16(1), 122-130. https://doi.org/10.1075/ni.16.1.16geo

Georgakopoulou, A. (2007). Small Stories, Interaction and Identities. Amsterdam: John Benjamins. https://doi.org/10.1075/sin.8

Goffman, E. (1979). Footing. Semiotica, 25(1/2), 1-29. https://doi.org/10.1515/semi.1979.25.1-2.1

Goodwin, C. (1984). Notes on story structure and organization of participation. In

J.M. Atkinson \& J. Heritage (Eds.), Structures of social action: Studies in conversation analysis (pp. 225-246). London/New York: Cambridge University Press.

Hanks, W.F. (1987). Discourse Genres in a Theory of Practice. American Ethnologist, 14(4), 668-692. https://doi.org/10.1525/ae.1987.14.4.02a00050

Hyon, S. (1996). Genre in Three Traditions: Implications for ESL. TESOL quarterly, 30 (4), 693-722. https://doi.org/10.2307/3587930

Hyvärinen, M. (2015). Analyzing narrative genres. In A. De Fina \& A. Georgakopoulou (Eds.), The Handbook of Narrative Analysis (pp. 178-193). Chichester: Wiley Blackwell.

Hyvärinen, M., Hydén, L.-C., Saarenheimon, M., \& Tamboukoun, M. (2010). Beyond narrative coherence: An introduction. In M. Hyvärinen, L.-C. Hydén, M. Saarenheimon \& M. Tamboukoun (Eds.), Beyond narrative coherence (pp. 1-15). Amsterdam: John Benjamins. https://doi.org/10.1075/sin.11.01hyv

Johnstone, B. (2001). Discourse analysis and Narrative. In D. Schiffrin, D. Tannen \& H. Hamilton (Eds.), The handbook of discourse analysis (pp. 635-649). Malden: Blackwell.

Kitagawa, C., \& Lehrer, A. (1990). Impersonal uses of personal pronouns. Journal of Pragmatics, 14(5), 739-759. https://doi.org/10.1016/0378-2166(90)90004-W

Labov, W. (1982). Speech Actions and Reactions in Personal Narrative. In D. Tannen (Ed.), Analyzing Discourse: Text and Talk (pp. 219-247). Georgetown University Press: Washington DC.

Labov, W. (2011). Narratives of Personal Experience. In P. Hogan (Ed.), Cambridge Encyclopedia of the Language Sciences (pp. 546-548). Cambridge: Cambridge University Press.

Labov, W., \& Waletzky, J. (1966). Narrative Analysis: oral versions of personal experience. In J. Helm (Ed.), Essays on the Verbal and Visual Arts (pp. 12-44). Seattle: Universiy of Washington Press.

Lerner, G.H. (1992). Assisted storytelling: Deploying shared knowledge as a practical matter. Qualitative Sociology, 15(3), 247-271. https://doi.org/10.1007/BFoo990328

Linde, C. (1993). Life Stories: The creation of coherence. Oxford/New York: Oxford University Press.

Mandelbaum, J. (1987). Couples sharing stories. Communication Quarterly, 35(2), 144-170. https://doi.org/10.1080/01463378709369678

Martin, J.R., \& Rose, D. (2008). Genre Relations: Mapping culture. London: Equinox.

Minami, M., \& McCabe, A. (1995). Rice balls and bear hunts: Japanese and North American family narrative patterns. Journal of Child Language, 22(2), 423-445. https://doi.org/10.1017/S0305000900009867 
Minister, K. (1991). A Feminist Frame for the Oral History Interview. In S. Berger Gluck \& D. Patai (Eds.), Women's Words: the feminist practice of oral history (pp. 27-42). New York: Routledge.

Norrick, N. R. (2000). Conversational narrative: Storytelling in everyday talk. Amsterdam: John Benjamins. https://doi.org/10.1075/cilt.203

Norrick, N.R. (2004). Humor, tellability, and conarration in conversational storytelling. Text, 24(1), 79-111. https://doi.org/10.1515/text.2004.005

Norrick, N. R. (2005). The dark side of tellability. Narrative Inquiry, 15(2), 323-343. https://doi.org/10.1075/ni.15.2.07nor

Norrick, N.R. (2007). Conversational storytelling. In D. Herman (Ed.), The Cambridge Companion to Narrative (pp. 127-141). Cambridge: Cambridge University Press. https://doi.org/10.1017/CCOL0521856965.009

Norrick, N. R. (2013a). Narratives of vicarious experience in conversation. Language in Society, 42(4), 385-406. https://doi.org/10.1017/Soo47404513000444

Norrick, N. R. (2013b). Stories of vicarious experience in speeches by Barack Obama. Narrative Inquiry, 23(2), 283-301. https://doi.org/10.1075/ni.23.2.04nor

Norrick, N. R. (2018). Negation in narrative: Why say what didn't happen? Narrative Inquiry, 28(2), 373-395. https://doi.org/10.1075/ni.17028.nor

O'Connor, P.E. (1994). 'You could feel it through the skin': Agency and positioning in prisoners' stabbing stories. Text, 14(1), 45-75. https://doi.org/10.1515/text.1.1994.14.1.45

Ochs, E., \& Capps, L. (2001). Living narrative: Creating lives in everyday storytelling. Cambridge, MA: Harvard University Press.

Page, R. (2010). Re-examining narrativity: small stories in status updates. Text \& Talk, 30 (4), 423-444. https://doi.org/10.1515/text.2010.021

Page, R., Harper, R., \& Frobenius, M. (2013). From small stories to networked narrative: The evolution of personal narratives in Facebook status updates. Narrative Inquiry, 23(1), 192-213. https://doi.org/10.1075/ni.23.1.10pag

Peterson, C., \& McCabe, A. (1983). Developmental Psycholinguistics: Three Ways of Looking at a Child's Narrative. New York: Plenum. https://doi.org/10.1007/978-1-4757-0608-6

Prince, G. (1982). Narratology. The form and functioning of narrative. Berlin: Mouton Publishers. https://doi.org/10.1515/9783110838626

Prince, G. (1992). Narrative as theme. Lincoln: University of Nebraska Press.

Riessman, C. K. (1993). Narrative analysis. London: Sage.

Sacks, H. (1986). On the analyzability of stories by children. In J. J. Gumperz \& D. Hymes (Eds.), Directions in sociolinguistics: the ethnography of communication (pp. 325-345). Oxford: Basil Blackwell.

Sacks, H. (1992). Lectures on Conversation (2 vols, edited by Gail Jefferson with introduction by Emanuel A. Schegloff). Oxford, UK/Cambridge, USA: Blackwell.

Schoofs, K., \& Van De Mieroop, D. (2019). Adjusting to new "truths": The relation between the spatio-temporal context and identity work in repeated WWII-testimonies. Narrative Inquiry, 29(2), 268-292. https://doi.org/10.1075/ni.19020.sch

Shuman, A. (2005). Other People's Stories: Entitlement Claims and the Critique of Empathy. Urbana Il.: University of Illinois Press.

Shuman, A. (2015). Story ownership and entitlement. In A. De Fina \& A. Georgakopoulou (Eds.), The Handbook of Narrative Analysis (pp. 38-56). Chichester: Wiley Blackwell.

Stirling, L., \& Manderson, L. (2011). About you: Empathy, objectivity and authority. Journal of Pragmatics, 43(6), 1581-1602. https://doi.org/10.1016/j.pragma.2010.12.002 
Swales, J. (1990). Genre Analysis: English in Academic and Research Settings. Cambridge: Cambridge University Press.

Toolan, M.J. (2001). Narrative: A Critical Linguistic Introduction (2nd ed.). London: Routledge.

Trinch, S.L. (2003). Latinas' Narratives of Domestic Abuse: Discrepant Versions of Violence. Amsterdam: John Benjamins. https://doi.org/10.1075/impact.17

Van De Mieroop, D. (2011). Identity negotiations in narrative accounts about poverty. Discourse \& Society, 22(5), 565-591. https://doi.org/10.1177/0957926511405423

Van De Mieroop, D. (2015). Social Identity Theory and the Discursive Analysis of Collective Identities in Narratives. In A. De Fina \& A. Georgakopoulou (Eds.), The Handbook of Narrative Analysis (pp. 408-428). Chichester: Wiley-Blackwell.

Van De Mieroop, D. (2019). Implying identities through narratives of vicarious experience in job interviews. Journal of Pragmatics, 152, 61-75. https://doi.org/10.1016/j.pragma.2018.01.006

Van De Mieroop, D. (forthcoming). Applying the Narrative Dimensions Model. VAKKI Publications 11, Workplace Communication III. Available at: http://www.vakki.net /publications/

Van De Mieroop, D., \& Clifton, J. (2014). The discursive management of identity in interviews with female former colonials of the Belgian Congo: Scrutinizing the role of the interviewer. Pragmatics, 24(1), 131-155. https://doi.org/10.1075/prag.24.1.06mie

Van De Mieroop, D., \& Clifton, J. (2016). Life Stories. In J.-O. Östman \& J. Verschueren (Eds.), Handbook of Pragmatics (pp. 1-20). Amsterdam: Benjamins. https://doi.org/10.1075/hop.20.lif2

Van De Mieroop, D., Miglbauer, M., \& Chatterjee, A. (2017). Mobilizing master narratives through categorical narratives and categorical statements when default identities are at stake. Discourse \& Communication, 11(2), 179-198. https://doi.org/10.1177/1750481317691867

Vindrola-Padros, C., \& Johnson, G.A. (2014). The Narrated, Nonnarrated, and the Disnarrated: Conceptual Tools for Analyzing Narratives in Health Services Research. Qualitative Health Research, 24(11), 1603-1611. https://doi.org/10.1177/1049732314549019

\title{
Address for correspondence
}

\author{
Dorien Van De Mieroop \\ KU Leuven \\ Faculty of Arts \\ Blijde-Inkomststraat 21 \\ P.O. box 3308 \\ B-30oo Leuven \\ Belgium \\ dorien.vandemieroop@kuleuven.be \\ https://orcid.org/oooo-0oo2-1704-2165
}




\section{Publication history}

Date received: 28 June 2019

Date accepted: 9 June 2020

Published online: 28 July 2020 